\title{
THE DATA MINING APPLIED FOR THE PREDICTION OF HIGHWAY ROUGHNESS DUE TO OVERLOADED TRUCKS
}

\author{
Andri Irfan Rifai ${ }^{1 *}$, Sigit P. Hadiwardoyo ${ }^{1}$, Antonio Gomes Correia ${ }^{2}$, Paulo Pereira ${ }^{3}$, Paulo \\ Cortez ${ }^{4}$ \\ ${ }^{1}$ Department of Civil Engineering, Faculty of Engineering, Universitas Indonesia, Kampus Baru UI \\ Depok, Depok 16424, Indonesia \\ ${ }^{2}$ Institute for Sustainability and Innovation in Structural Engineering, University of Minho, \\ Guimarães, Portugal \\ ${ }^{3}$ Centre for Territory, Environment, and Construction, University of Minho, Guimarães, Portugal \\ ${ }^{4}$ Centre Algorithmic, University of Minho, Guimarães, Portugal
}

(Received: June 2015 / Revised: August 2015 / Accepted: October 2015)

\begin{abstract}
Currently, the quality of the Indonesian national road network is inadequate due to several constraints, including overcapacity and overloaded trucks. The high deterioration rate of the road infrastructure in developing countries along with major budgetary restrictions and high growth in traffic have led to an emerging need for improving the performance of the highway maintenance system. However, the high number of intervening factors and their complex effects require advanced tools to successfully solve this problem. The high learning capabilities of Data Mining (DM) are a powerful solution to this problem. In the past, these tools have been successfully applied to solve complex and multi-dimensional problems in various scientific fields. Therefore, it is expected that DM can be used to analyze the large amount of data regarding the pavement and traffic, identify the relationship between variables, and provide information regarding the prediction of the data. In this paper, we present a new approach to predict the International Roughness Index (IRI) of pavement based on DM techniques. DM was used to analyze the initial IRI data, including age, Equivalent Single Axle Load (ESAL), crack, potholes, rutting, and long cracks. This model was developed and verified using data from an Integrated Indonesia Road Management System (IIRMS) that was measured with the National Association of Australian State Road Authorities (NAASRA) roughness meter. The results of the proposed approach are compared with the IIRMS analytical model adapted to the IRI, and the advantages of the new approach are highlighted. We show that the novel data-driven model is able to learn (with high accuracy) the complex relationships between the IRI and the contributing factors of overloaded trucks.
\end{abstract}

Keywords: Data mining; Overload; Pavement maintenance; Pavement roughness; Prediction

\section{INTRODUCTION}

The Indonesian road network (approximately 500,000 km, with 40,000 km of national paved roads), currently is of inadequate quality, with several constraints, mainly due to overcapacity and overloaded trucks. This trucks overload in Indonesia, however, has been considered as a factor of environmental conditions (Hadiwardoyo et al., 2012). The high deterioration rate of the road infrastructure in developing countries, major budgetary restrictions, and high traffic

\footnotetext{
* Corresponding author's email: andrirfan@yahoo.com, Tel. +62-21-7270029, Fax.+62-21-7270028

Permalink/DOI: http://dx.doi.org/10.14716/ijtech.v6i5.1186
} 
growth have led to an emerging need to improve the performance of the highway maintenance system. Pavement condition prediction models play a critical role in any Pavement Management System (PMS). To enhance the performance of a PMS, the successful prediction of the pavement performance is very important (Karlaftis \& Badr, 2015). Accurate prediction models assist road agencies in performing cost-effective maintenance or rehabilitation at the appropriate time and improving the overall pavement condition within a specific budget limitation.

Traffic overload is considered to be a common issue in developing countries (Ede, 2014). This issue is continuously occurring, and the Indonesian Government seems to be unable to prevent it. The factors behind overloaded trucks are the limitation of transportation and the attempt to minimize transportation cost. In addition, the continuous use of overloaded trucks causes rapid and severe damage to the road. The greatest contributor to the decrease of road life-performance is overloaded trucks (Sianipar \& Dowaki, 2014). The decrease of a road's life-performance due to normal loading is different than the decrease caused by overloaded trucks, and the difference between these two is not linear.

In implementing road maintenance management, the Directorate General of Highway (DGH)Indonesia has already developed the Integrated Indonesia Road Management System (IIRMS), which contains important data regarding the road network (DGH, 2012), but the system is only considered to be a partial success. The problems found in this system are related to poor data quality and the relevance of the outputs used for the preparation of maintenance plans and programs. In addition, the IIRMS has reached a technical critical point, where improvement, further development, or replacement of the system is necessary. The core data required by the IIRMS is provided by a number of surveys that are normally performed on an annual basis, such as the Road Network Inventory, Road Condition Survey (RCS), Road Inventory, and International Roughness Index (IRI) (DGH, 2012).

Determining the IRI is a complex pavement surface problem due to the condition of the pavement and the large number of parameters involved. Thus, the use of artificial intelligence tools, in particular the application of Data Mining (DM) techniques (Cortez, 2010), has great potential within this domain. Some examples of DM applications in the civil engineering domain include: the modelling pavement present serviceability index which uses DM (Terzi, 2006); studying the integration of Geographic Information System and DM to enhance pavement management (Zhou et al., 2010); the prediction of jet grouting with DM using artificial neural network-based models (Tinoco et al., 2011); and a classification of functional road using DM (D'Andrea et al., 2014). To the best of our knowledge, DM has not yet been applied to pavement roughness prediction, namely the prediction of the IRI.

The main objective of this research is to develop a predictive model of the national road's IRI based on the data that has been collected by the IIRMS. The further objective of this research is to compare the national road's IRI prediction model in the normal-loading state and in the overloading state.

\section{PAVEMENT MANAGEMENT SYSTEM}

The management process involves planning, implementation, and control. This process also applies to the PMS, where the stakeholders should ensure that, within a certain period of time, the function of the pavement remains in a reliable condition. The objective of transportation infrastructure management is to provide optimal maintenance, rehabilitation, and replacement policies for a system of facilities (roads, bridges, tunnels, etc.) over a planning horizon (Medury \& Madanat, 2015). The PMS consists of several stages, with the main stage involving the selection, development, and optimization of maintenance strategies. The PMS applies a two- 
step processing program to generate various strategies and further optimization, and the optimization process provides assistance in selecting the cost-optimal maintenance strategy under the allocated budget (Ai et al., 2015). To obtain the correct strategy, the decision maker must be able to interpret the existing data and, at the same time, predict the future surface conditions.

In accordance with the needs of a modern management system, the DGH continues to improve their capacity by refining the PMS. According to the data, the management system is composed of a series of processes that assist managers in conducting their tasks and duties; in the case of a highway agency, the manager is responsible for the improvement and preservation of the road infrastructure. The core data required by the IIRMS is provided by a number of surveys that are normally performed on an annual basis (DGH, 2012).

\subsection{The International Roughness Index}

The pavement surface condition in Indonesia is measured by the IRI. The IRI was developed in 1986 by the World Bank and was based on the extension of the National Cooperative Highway Research Program (NCHRP) concept. The IRI was first introduced in the International Road Roughness Experiment held in Brazil (Sayers \& Karamihas, 1995). ASTM E 1926 defines the standard procedure for computing the IRI from longitudinal profile measurements based upon a mathematical model referred to as a quarter-car model. The IRI has been accepted internationally as an indicator of a road's serviceability level, which can continuously be calibrated for different regions and times. In addition, the IRI has more real value compared to other performance pavement parameters due to the objective measurement results. The IRI is calculated based on an established computer algorithm and thus is not subjective (Arhin et al., 2015). Haas (2003) grouped several performance prediction models into classes, which indicate their basis as follows: empirical, mechanistic-empirical, and subjective. In the implementation of the IRI, the IIRMS records the IRI results from the field measurements every year, and also collects the data of Equivalent Single Axle Load (ESAL), cracks, potholes, rutting, and long cracks. Even with annual surveys, there are still some incomplete data, necessitating the development of models that can produce an interpretation of existing data. Further development of the IRI value is the main indicator in determining the level of a road's serviceability in Indonesia and is also a consideration for the policy makers in determining the maintenance budget.

\subsection{Overloaded Trucks}

The traffic served by national roads is characterized by a number of different vehicle types, with variations for different vehicle loads. Weak oversight has led to the ignorance of the road users regarding the determined maximum axle load limits. In Indonesia, overloads occur when the weight of a truck's load exceeds the maximum allowable limit of 10 tons for road class I or II, and 8 tons for road class III. Increased numbers of overload cases on the national road both reduce the road's serviceability and increase the burden of maintenance costs. The vehicles that exceed the axle limit cause significant damage to the pavement, thereby increasing the cost of pavement construction and rehabilitation (Pais et al., 2013).

The efforts undertaken by the DGH in recent times appear to be unsuccessful because the uncontrolled use of overloaded trucks on the national roads has significantly increased. Based on the data recorded by the DGH's weight-in-motion system, overloaded trucks most frequently occur in the North Corridor of Java Island; thus this region requires special attention. Excessive load tolerance policy on the basis of percentage of permitted maximum load for each type of truck is considered inappropriate because some specific types of trucks will significantly accelerate the attainment of the cumulative ESAL and the decrease of pavement service life (Hadiwardoyo, 2012). The level of damage caused by overloaded trucks in Indonesia influences 
the overall condition of the national roads. Rusbintardjo (2013) shows that $150 \%$ overloaded single, dual, and triple axle trucks will bring about 500\%, 135\%, and $122 \%$ levels of damage, respectively. The results of the calculation using VDF also resulted in similar results, namely, 47.20, 10.30, and 7.99 times the normal deterioration of the pavement. Similar road damage also occurs in other countries; overloaded trucks have been identified as one of the major contributors to road pavement damage in Malaysia (Karim et al., 2014) and in Nigeria (Ede, 2014).

\section{METHODOLOGY}

$\mathrm{DM}$ is used to analyze raw and complex data and semi-automatically extract high-level information for the decision maker (Tinoco et al., 2011). Figure 1 provides the overview of the DM process, also known as knowledge discovery in a database. This process begins with the selection of the database on which the research study is developed and ends with the presentation of the knowledge discovered.

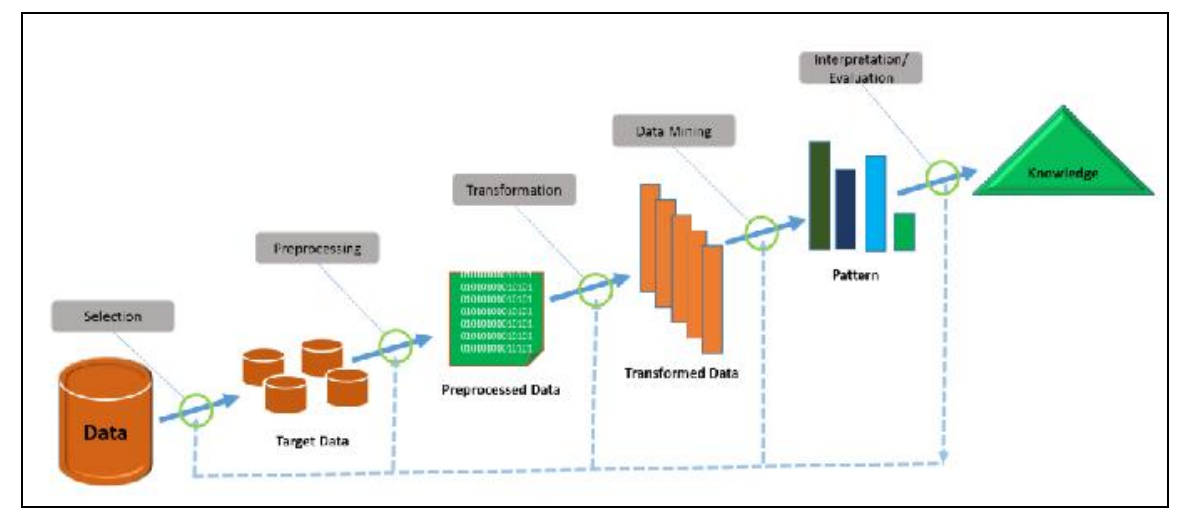

Figure 1 Steps of the DM process - adapted from Cortez (2010)

Regression is one of the main tasks of DM. This task consists of mapping several inputs (or independent variables) to a given numeric output (the dependent variable) (Tinoco et al., 2011). Several regression approaches of DM are used, including Multiple Regression (MR), Artificial Neural Networks (ANNs), and the Support Vector Machine (SVM). Such approaches have been used to conduct IRI predictions by utilizing the Structural Number (SN) and Age data (Rifai et al., 2014). In this research study, IRI prediction is developed by utilizing traffic data, initial performance, and distress. The factors that have been identified are age, Initial IRI (IRI $)_{0}$, ESAL, cracks, potholes, rutting, and long cracks. The availability of the data in the IIRMS is important for the policy makers in the DGH. Therefore, it is necessary to interpret large amounts of data that have been collected by the system.

In the present research, DM was implemented in the R software (http://www.r-project.org/) under the rminer library (Cortez, 2010). $\mathrm{R}$ is an open-source computational environment and high-level language that integrates powerful statistical and graphical features for databases. $\mathrm{R}$ adopts a very flexible and objective-oriented design. The rminer library consists of several regression techniques, each one with its own advantages. MR is easy to interpret due to its additive nature; ANNs and the SVM require more computational resources, but are capable of modeling more complex data.

\subsection{Pavement Performance Data}

The models were verified using the data from the IIRMS. The data were extracted at the Directorate of Planning, DGH-Indonesia and processed at the Centre for Territory, Environment, and Construction and the Centre Algorithmic, University of Minho, Portugal. The 
dataset from the West Java (WJ) highway networks includes 2,475 results, derived from 165 highway segments of flexible pavement and 8 input parameters, which are referred to as the influential parameters in empirical studies of pavement roughness. Those parameters are given an order code as input, as presented in Table 1 below.

Table 1 Input code

\begin{tabular}{clll}
\hline No & \multicolumn{1}{c}{ Code } & \multicolumn{1}{c}{ Measurement } & \multicolumn{1}{c}{ Description } \\
\hline Input 1 & IRI & meter $/$ kilometer $(\mathrm{m} / \mathrm{km})$ & International Roughness Index \\
Input 2 & Age & years & Age of Pavement \\
Input 3 & IRI $_{0}$ & meter $/$ kilometer $(\mathrm{m} / \mathrm{km})$ & Initial IRI \\
Input 4 & ESAL & number & Equivalent Single Axle Load \\
Input 5 & Crack & square meter $\left(\mathrm{m}^{2}\right)$ & Cracks predominantly parallel to \\
& & pavement centerline \\
Input 6 & Potholes & number & Record number of potholes \\
Input 7 & Rut & millimeters $(\mathrm{mm})$ & Record maximum rut depth \\
Input 8 & Long Crack & meter $(\mathrm{m})$ & Record the length \\
\hline
\end{tabular}

The age data are obtained from the road pavement history. Roughness data, in the form of the IRI, was collected every year using the NAASRA roughness meter and then compiled in the IIRMS database program. The NAASRA roughness meter measures the relative movement between the axle and the vehicle body at a given speed. Maintenance can be carried out between two consecutive measurements of the IRI; however, in this case the other independent parameter will also reflect this maintenance action. ESAL data are obtained from the annual traffic surveys. Crack, pothole, rutting, and long crack data are obtained from visual surveys and detailed measurements in the field using the standard survey form. The data chosen for this research is the data from 2000 until 2014. The statistics of the parameters used in this paper are presented in Table 2.

Table 2 Statistics of the database values

\begin{tabular}{lcccrrrr}
\hline & $\begin{array}{c}\text { Age } \\
(\text { years })\end{array}$ & $\begin{array}{c}\mathrm{IRI}_{0} \\
(\mathrm{~m} / \mathrm{km})\end{array}$ & ESAL & $\begin{array}{c}\text { Cracking } \\
\left(\mathrm{m}^{2}\right)\end{array}$ & $\begin{array}{c}\text { Potholes } \\
(\text { numbers })\end{array}$ & $\begin{array}{c}\text { Rutting } \\
(\mathrm{mm})\end{array}$ & $\begin{array}{c}\text { Long Crack } \\
(\mathrm{m})\end{array}$ \\
\hline Min & 1 & 1.50 & $721,418.14$ & 10.00 & 0.00 & 2.2 & 2.5 \\
Max & 15 & 5.99 & $1,676,597.84$ & 45.00 & 19.00 & 24.0 & 29.0 \\
Aver. & 8 & 3.59 & $1,211,500.21$ & 23.90 & 11.86 & 12.0 & 17.0 \\
Dev. & 4.32 & 1.49 & $287,399.65$ & 8.01 & 5.22 & 4.2 & 3.5 \\
\hline
\end{tabular}

\subsection{Data Mining Models}

In the present study, three DM Techniques were used to model IRI prediction: MR, ANNs, and the SVM. All of the experiments were conducted using the $\mathrm{R}$ statistical environment and the rminer library (Cortez, 2010), which facilitated the application of DM techniques in the R. The MR model was defined by Equation 1 (Hastie et al., 2001) as:

$$
y=\beta_{0}+\sum_{i=1}^{n} \beta_{i} \times x_{i}
$$

where $\left(\mathrm{x}_{1}, \ldots, \mathrm{x}_{\mathrm{i}}\right)$ are the input parameters and $\left(\beta_{0}, \beta_{1, \ldots,} \beta_{i}\right)$ are the coefficients to be adjusted, normally using the least squares technique. Due to its additive nature, this model is easy to interpret and it is widely used in regression tasks. 
ANNs consist of simple elements operated in parallel. These elements are inspired by the biological neuron system. ANNs can be set to perform a certain function by adjusting the connection values between the elements. Generally, ANNs are adjusted or trained so that a certain input can be directed to a specific output. The general model is given by the following equation (Cortez, 2010):

$$
\hat{y}=w_{o, 0}+\sum_{j=I+1}^{0-1}\left(\sum_{i=1}^{I} x_{i} \times w_{j, i} \times w_{j, 0}\right) \times w_{o, i}
$$

where $w_{j, i}$ represents the weight of the connection from neuron $j$ to the unit $i$ (if $j=0$, then the connection is biased), $o$ corresponds to an output unit, and $I$ is the number of input neurons.

The SVM model in DM produces a smart interpretation model based on the collected data with a certain condition and uses an algorithm following a certain pattern and space according to Equation (3). A SVM has theoretical advantages over ANNs, such as the absence of local minima in the learning phase, i.e., the model always converges to the optimal solution. The main idea of a SVM is to transform the input data into a high-dimensional feature space by using nonlinear mapping $\mathrm{U}$, which is normally unknown. Next, the SVM finds the best hyperplane of linear separation within the feature space (Cortez, 2010). This transformation depends on the kernel function adopted. The Gaussian kernel is the most popular and adopted in this research:

$$
K\left(x, x^{\prime}\right)=e^{\left(-\gamma \times\left\|x-x^{\prime}\right\|^{2}\right)}, \quad \gamma>0
$$

Under this setup, the performance is affected by two parameters: $\gamma$ - the parameter of the kernel and the $\epsilon$. The kernel parameter $(\gamma)$ has the highest impact on the SVM performance.

Several error metrics can be used to evaluate the performance of regression models, namely, the mean absolute error (MAD), the root mean squared error (RMSE), and the coefficient of determination $\left(\mathrm{R}^{2}\right)$. These coefficients are defined as:

$$
\begin{gathered}
M A D=\frac{\sum_{i=1}^{N}|y-\hat{y}|}{N} \\
R M S E=\sqrt{\frac{\sum_{i=1}^{N}\left(y-\hat{y}^{2}\right.}{N}} \\
R^{2}=\left(\frac{\sum_{i=1}^{N}(y-\bar{y}) \times(\hat{y}-\hat{\bar{y}})}{\sum_{i=1}^{N}(y-\bar{y})^{2} \times \sum_{i=1}^{N}(\hat{y}-\hat{\bar{y}})^{2}}\right)
\end{gathered}
$$

where $y$ denotes the desired value, $\hat{y}$ is the predicted value, and $\vec{y}$ represents the mean values of these variables. Lower values of the MAD and RMSE correspond to a higher predictive capacity, while the $\mathrm{R}$ value should be close to one. If it is acceptable to commit a few extreme errors while maintaining the average of prediction with a good approximation, then the MAD is the optimal measure. Otherwise, the RMSE measure should be used. In this research, the ANNs and SVM hyper-parameters $(\mathrm{H}$ and $\gamma)$ were optimized using a grid search of $\mathrm{H}(2,4, \ldots, 10)$ and $\gamma\left(2^{-15}, 2^{-13}, \ldots, 2^{3}\right)$ (Hastie et al., 2001). To avoid overfitting, the training data were further divided into a training set $(80 \%)$ and a validation set (20\%). After selecting the best parameter, the model was retrained with all the training data. Then, the importance of the relative was measured by applying the sensitivity analysis method proposed by Cortez and Embrechts (2013). 


\section{RESULTS AND DISCUSSION}

\subsection{IIRMS Analytical Model}

The IIRMS consists of a database system, a road maintenance planning system, a road maintenance programming system, and a road maintenance budgeting system. To obtain IRI predictions, the IIRMS method can be used in Equation 7 with RCS data (DGH, 2012).

$$
I R I=0,98 \times e^{m \cdot \tau}\left\{I R I_{0}+135 S N C K^{-5} \cdot N E_{t}+0,143 R D S_{t}+0,0068 \text { Crack }_{t}+0,056 P A T_{t}\right\}
$$

$S N C K$ is the Modified SN by AASHTO, $N E$ is the number of ESAL, RDS denotes rutting, PAT denotes patching, and $t$ is the age of the pavement in years.

The quality of the prediction obtained by applying the IIRMS model is presented in Figure 2, which shows that the IIRMS's IRI prediction formula resulted in less accurate data. This performance is confirmed by the values of $\mathrm{R}^{2}$, MAD, and RMSE (Figure 3). Among the 20 runs performed, the SVM hyper-parameters that best fit the data are $\epsilon=0.07 \pm 0.01$ and $\gamma=$ $0.05 \pm 0.00$. The ANN hyper-parameters that best fit the data are $H=3 \pm 1$. Compared with other DM models, the results from these DM models are considered more reliable.

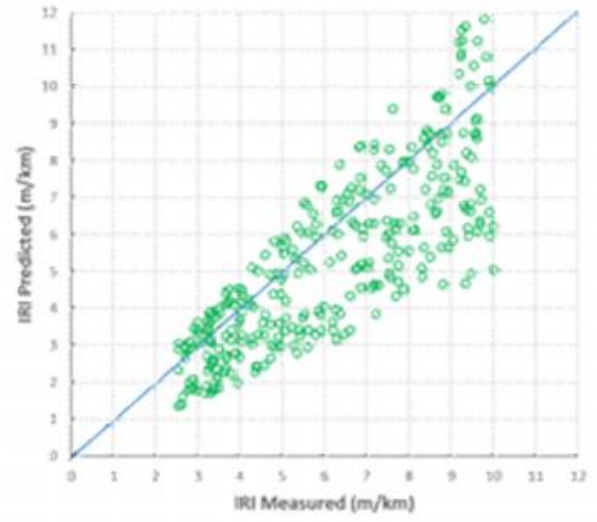

Figure 2 IRI values using the IIRMS

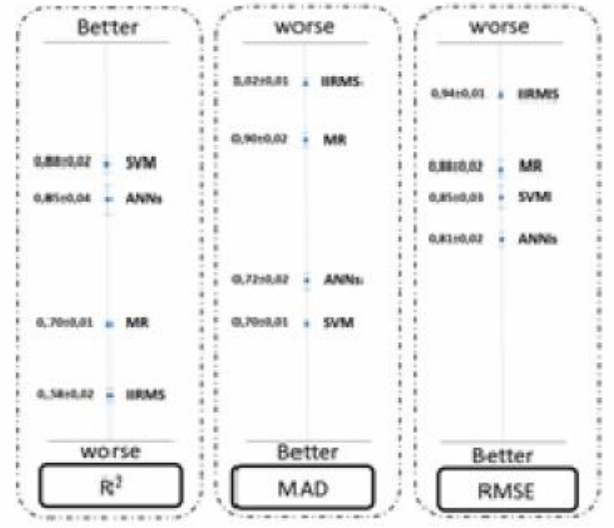

Figure 3 Performance measured from all of the models used

\subsection{Data Mining Techniques}

For this research, three DM techniques were trained using the dataset that has been previously described to perform the predictions. Among the three DM algorithms tested, the best results were obtained by the SVM and ANNs models, which had similar performances. The performances of these models were confirmed by the $\mathrm{R}^{2}$, MAD, and RMSE values (see Figure 3 ). The lower the MAD and RMSE values, the better the predictive model, while a perfect model should have a $\mathrm{R}^{2}$ value close to 1.0. The results are presented in terms of the average of the runs and with the respective $95 \%$ confidence intervals according to a t-student distribution. The SVM was adopted as the reference model because it had a lower level of variation among the several runs executed (over a total of 20 runs).

By analyzing Figure 4 (which shows the relationships between measured versus predicted values using the SVM model), it is concluded that the variables can be achieved using the parameters that have been studied, i.e., Age, IRI $\mathrm{I}_{0}$, ESAL, Cracking, Pothole, Rutting, and Long crack. Figure 4(a) shows scatterplots of the results of the learning stage of the SVM model, and Figure 4(b) shows the results of an iteration for the validation stage of the SVM model.

In the validation stage, the features of the rminer library were used to describe and obtain the relative contribution value of each input value. Figure 5 shows the importance attributed by 
SVM to each input parameter that was obtained by applying sensitivity analysis. Based on the figure, it is concluded that the ranking of the variables is in the following order: ESAL, Long crack, Pothole, Age, Crack, $\mathrm{IRI}_{0}$, and Rutting. At the learning and validation stage, ESAL has the highest contribution level to the value of the IRI.

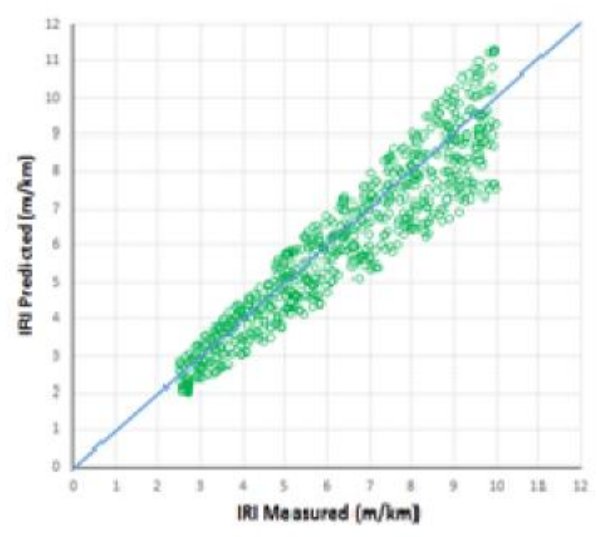

(a) Learning stage

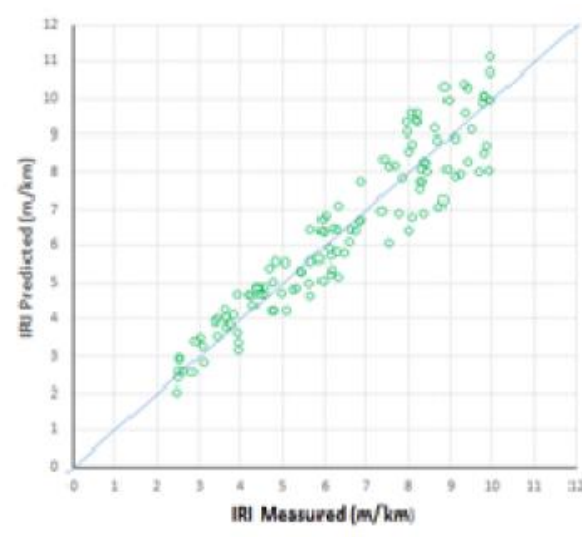

(b) Validation stage

Figure 4 Predicted versus measured IRI values using the SVM model

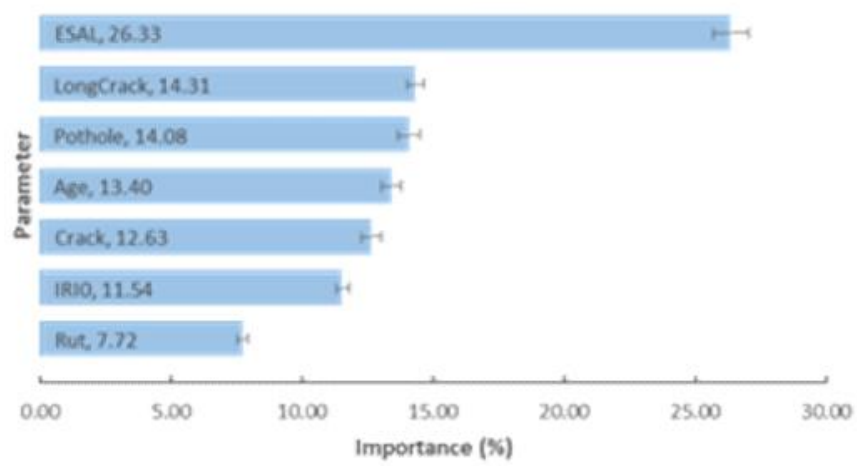

Figure 5 Distribution of the contributions of the input parameters

Individual contributions of each input are shown in Table 3. In the same table, the contributions are grouped for Traffic (39.73\%), Initial Performance (11.54\%), and Distress (48.76\%)

Table 3 Relative contribution of the input parameters for the final IRI Value

\begin{tabular}{lccc}
\hline \multicolumn{1}{c}{ Input } & Contribution (\%) & Group & Group Contribution (\%) \\
\hline ESAL & 26.33 & Traffic & $39.73 \%$ \\
Age & 13.40 & Initial Performance & $11.54 \%$ \\
\hline IRI $_{0}$ & 11.54 & & \\
\hline Long Crack & 14.31 & Distress & $48.76 \%$ \\
Pothole & 14.08 & & \\
Crack & 12.63 & & \\
Rutting & 7.72 & & \\
\hline
\end{tabular}

The ESAL possesses the highest importance value in the contribution towards the IRI value because the number of ESAL greatly affects the changes in the surface condition of flexible pavement. The high level of repetitive and heavy loads causes changes in the road surface. 
Traffic growth and the age of pavement are the largest factors in the calculations of the IRI value. Meanwhile, other parameters such as long crack, pothole, and crack have a fairly balanced importance value in affecting the IRI value.

\subsection{Simulation Model of Overloaded Trucks}

Each road of the WJ highway network has different characteristics, with different load factors. Furthermore, each group of modeling results is compared with the results of measurements of the weight bridge in these segments. The measurement results are presented in Table 4 . The network is separated into four overload categories, and the measurement result with the highest overload percentage is Group 1, which is passed by as much as $38 \%$ of the traffic of overloaded trucks; thus, it is categorized as heavy overload. Group 2 is hereafter referred to as a medium overload, with the amount of overloaded trucks passing by reaching $30 \%$. Group 3, which is the main axis across the North Corridor, accounts for as much as $29 \%$ of the traffic of overloaded trucks, but is $17 \%$ below the $20 \%$ of overloaded trucks case. The remaining segments of the national road network in WJ are averaged at $17 \%$ of the overload and are included in Group 4 as normal.

Table 4 Load factor simulation measurement results

\begin{tabular}{|c|c|c|c|c|c|c|}
\hline \multirow{2}{*}{ Networks } & \multicolumn{4}{|c|}{ Load Factor (\%) } & \multirow{2}{*}{$\begin{array}{c}\text { Total } \\
(\%)\end{array}$} & \multirow{2}{*}{ Category } \\
\hline & $\leq 100$ & $100-120$ & $120-140$ & $\geq 140$ & & \\
\hline Group 1 & 62 & 9 & 11 & 18 & 100 & Heavy Overload \\
\hline Group 2 & 70 & 15 & 9 & 6 & 100 & Medium Overload \\
\hline Group 3 & 71 & 17 & 7 & 5 & 100 & Light overload \\
\hline Group 4 & 83 & 7 & 8 & 2 & 100 & Normal \\
\hline
\end{tabular}

The difference of the IRI value simulations for each of the load factor variables is shown in Figure 6. The simulation results showed that the difference of load factors will change the pavement's service life.

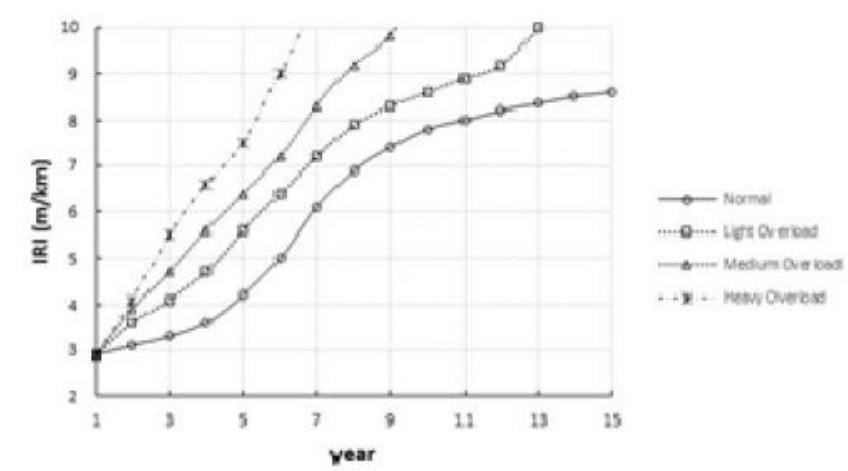

Figure 6 Predictive simulated load factor

The changes of the IRI value at the road segment with a heavy overload is over $4 \mathrm{~m} / \mathrm{km}$ in the second year; thus, it is concluded that in one year, the level of serviceability roads has passed the normal limits. The road with a normal load can last for 5 years, achieving a reduction of the IRI of a little over $4 \mathrm{~m} / \mathrm{km}$ at that point. The reduction of the serviceability levels is significantly influenced by the differences in the load factor of vehicles in each segment of the road network. 


\section{CONCLUSION}

The IIRMS analytical model is simple and exhibits good predictive capacity, but it requires more detailed analyses and has limitations on data accuracy $\left(\mathrm{R}^{2} \leq 0.7\right)$. By using $\mathrm{DM}$ techniques and, in particular, the SVM technique, a model with excellent predictive capacity for large data is obtained. It is also possible to predict the road performance level for several different load factors using the DM techniques. The proposed model also allows for the identification of the input parameters that control the behavior of the IRI, including ESAL, Long Crack, Pothole, Age, Crack, $\mathrm{IRI}_{0}$, and Rutting. Furthermore, the results showed that all of the DM techniques (MR, ANNs, and SVM) have a strong relationship $\left(\mathrm{R}^{2} \geq 0.7\right)$ and should be considered in the model. This model can be used in the PMS with several different loading conditions (heavy overload, medium overload, light overload, and normal load).

\section{ACKNOWLEDGEMENT}

We acknowledge the Directorate of Planning, DGH-Indonesia for providing the data for this research, and the Centre for Territory, Environment, and Construction and the Centre Algorithmic, University of Minho, Guimarães, Portugal for assistance in the research study.

\section{REFERENCES}

Ai, L., Dewen, L., Dong, L., Zeng, S., 2015. Research on Road Environment Construction of Pavement Management System. International Conference on Mechatronics, Electronic, Industrial and Control Engineering (MEIC 2015), pp. 38-41

Arhin, A.S., Williams, L.N., Ribbiso, A., Anderson, M.F., 2015. Predicting Pavement Condition Index using International Roughness Index in a Dense Urban Area. Journal of Civil Engineering Research, Volume 5(1), pp. 10-17

Cortez, P., 2010. Data Mining with Neural Networks and Support Vector Machines using the R/rminer Tool. In: Pemer, P. (Ed)., Advances in Data Mining: Applications and Theoretical Aspects. $10^{\text {th }}$ Industrial Conference on Data Mining, Berlin, Germany, LNAI 6171, Springer-Verlag, pp. 572-583

Cortez, P., Embrechts, M.J., 2013. Using Sensitivity Analysis and Visualization Techniques to Open Black Box Data Mining Models. Information Sciences, Volume 225, pp. 1-17

D’Andrea, A., Cappadona, C., La Rosa, G., Pallegrino, O., 2014. A Functional Road Classification with Data Mining Techniques. Transport, Volume 29(4), pp. 419-430

DGH, 2012. Directorate General Highway Annual Report 2012. Ministry of Public Works

Ede, A.N., 2014. Cumulative Damage Effects of Truck Overloads on Nigerian Road Pavement. International Journal of Civil and Environmental Engineering, IJCEE-IJENS Volume 14(1), pp. 21-26

Hastie, T., Tibshirani, R., Friedman, J., 2001. The Elements of Statistical Learning: Data Mining, Inference, and Prediction. Springer-Verlag, New York, USA

Haas, R., 2003. Good Technical Foundations are Essential for Successful Pavement Management. In: Proceedings of MAIREPAV 2003, Guimaraes, Portugal

Hadiwardoyo, S.P., Sumabrata, R.J., Berawi, M.A., 2012. Tolerance Limit for Trucks with Excess Load in Transport Regulation in Indonesia. Makara Journal of Technology, Volume 16(1), pp. 85-92

Karim, R.H., Ibrahim, N.I., Saifizul, A.A., Yamanaka, J., 2014. Effectiveness of Vehicle Weight Enforcement in a Developing Country using Weigh-in-motion Sorting System Considering Vehicle By-pass and Enforcement Capability. IATSS Research, Volume 37(2), pp. $124-129$ 
Karlaftis, A.G., Badr A., 2015. Predicting Asphalt Pavement Crack Initiation Following Rehabilitation Treatments. Transportation Research Part C: Emerging Technologies, Volume 55, pp. 510-517

Medury, A., Madanat, S., 2015. Incorporating Network Considerations into Pavement Management Systems. International Conference on Applications of Statistics and Probability in Civil Engineering, ICASP12 Vancouver, Canada, 12-15 July

Pais, J., Amorim, S., Minhoto, M., 2013. Impact of Traffic Overload on Road Pavement Performance. Journal Transportation Engineering, Volume 139(9), pp. 873-879

Rifai, A.I., Hadiwardoyo, S.P., Correia, A.G., Pereira, P., Cortez, P., 2014. Implementasi Data Mining untuk Mendukung Sistem Manajemen Perkerasan Jalan di Indonesia. Konferensi Regional Teknik Jalan Ke-13, Makassar

Rusbintardjo, 2013. The Influence of Overloading Truck to the Road Condition. In: Proceedings of the Eastern Asia Society for Transportation Studies, Volume 9, pp. 1-16

Sayers, M.W., Karamihas, S.M., 1995. The Little Book of Profiling. UMTRI, In: Sayers, W. (Ed)., On the Calculation of IRI from Longitudinal Road Profile.

Sianipar, C.P.M., Dowaki, K., 2014. Eco-burden in Pavement Maintenance: Effects from Excess Traffic Growth and Overload. Sustainable Cities and Society, Volume 12, pp. $31-45$

Terzi, S., 2006. Modeling the Pavement Present Serviceability Index of Flexible Highway Pavements using Data Mining. Journal of Applied Sciences, Volume 6(1), pp. 193-197

Tinoco, J., Correia, A.G., Cortez, P., 2011. Application of Data Mining Techniques in the Estimation of the Uniaxial Comprehensive Strength of Jet Grouting Columns over Time. Construction and Building Material, Volume 25(3), pp. 1257-1262

Zhou, G., Wang, L., Wang, D., Reichle, S., 2010. Integration of GIS and Data Mining Technology to Enhance the Pavement Management Decision Making. Journal of Transportation Engineering, Volume 136(4), pp. 332-341 